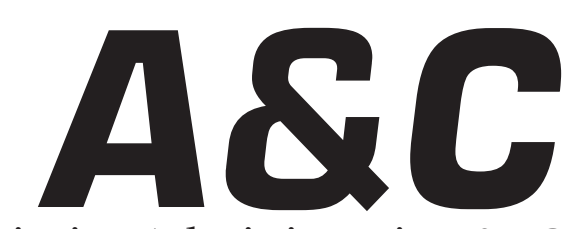

Revista de Direito Administrativo \& Constitucional

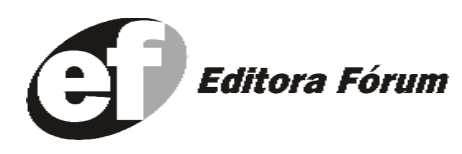

A\&C R. de Dir. Administrativo e Constitucional, Belo Horizonte, ano 4, n.15, p.1-256, jan./mar. 2004 
A\&C REVISTA DE DIREITO ADMINISTRATIVO E CONSTITUCIONAL

\section{IPDA}

Instituto Paranaense

de Direito Administrativo

Direção Geral

Romeu Felipe Bacellar Filho

Direção Editorial

Paulo Roberto Ferreira Motta

Direção Executiva

Emerson Gabardo

Conselho de Redação

Edgar Chiuratto Guimarães

Adriana da Costa Ricardo Schier

Célio Heitor Guimarães

Conselho Editorial

\begin{tabular}{|c|c|}
\hline Adilson Abreu Dallari & Manoel de Oliveira Franco Sobrinho \\
\hline Alice Gonzáles Borges & (in memoriam) \\
\hline Carlos Ari Sundfeld & Marçal Justen Filho \\
\hline Carlos Ayres Britto & Marcelo Figueiredo \\
\hline Carlos Delpiazzo & Márcio Cammarosano \\
\hline Lúcia Antunes Rocha & Maria Cristina Cesar de Oliveira \\
\hline io Bandeira de Mello & Nelson Figueiredo \\
\hline lèmerson Merlin Clève & Odilon Borges Junior \\
\hline Enrique Silva Cimma & Pascual Caiella \\
\hline Eros Roberto Grau & Paulo Eduardo Garrido Modesto \\
\hline Fabrício Motta & Paulo Henrique Blasi \\
\hline Ihermo Andrés Muñoz & Paulo Ricardo Schier \\
\hline Jorge Luís Salomoni & Pedro Paulo de Almeida Dutra \\
\hline José Carlos Abraão & Regina Maria Macedo Nery Ferrari \\
\hline ıardo Martins Cardoso & Rogério Gesta Leal \\
\hline José Luís Said & Rolando Pantoja Bauzá \\
\hline José Mario Serrate Paz & Sérgio Ferraz \\
\hline Pablo Cajarville Peruffo & Valmir Pontes Filho \\
\hline Juarez Freitas & Yara Stropa \\
\hline ulio Rodolfo Comadira & Weida Zancanner \\
\hline
\end{tabular}

Lúcia Valle Figueiredo

Luís Enrique Chase Plate

Os conceitos emitidos em trabalhos assinados são de responsabilidade de seus autores, que gozam de inteira

liberdade de opinião. e-mail para remessa de artigos, pareceres e contribuições: e.gab.@uol.com.br

ou conselho@editoraforum.com.br Endereço para envio de contribuições: Editora Fórum

Revista A\&C, Av. Afonso Pena, 2770, 15\%16 a andar, Funcionários, CEP 30130-007 - Belo Horizonte - MG

A\&C Revista de Direito Administrativo e Constitucional. Ano 3, n. 11, jan./mar. 2003. Belo Horizonte: Fórum, 2003.

Trimestral

ano 1, n.1, 1999 até ano 2, n.10, 2002 publicada pela Editora Juruá em Curitiba

ISSN: 1516-3210

1. Direito Administrativo. 2. Direito Constitucional. I. Fórum.

CDD: 342 CDU: 33.342
Editor responsável: Luis Cláudio Rodrigues Ferreira Projeto gráfico: Luis Alberto Pimenta

Diagramação: Luis Alberto Pimenta

Revisora: Olga M. A. Sousa

Pesquisa jurídica: Fátima Ribeiro - OAB/MG 74868 Bibliotecária: Nilcéia Lage de Medeiros -

CRB 1545/MG - 6 a região

(c) Editora Fórum Ltda., 2003.

Proibida a reprodução total ou parcial desta obra, por qualquer meio eletrônico, inclusive por processos xerográficos, sem autorização expressa do editor.

Distribuída em todo o território nacional

Assinaturas e comercialização:

Editora Fórum, Av. Afonso Pena, 2770, 15-16 andar, Funcionários, CEP 30130-007 - Belo Horizonte - MG Tel.: (31) 2121-4900 - 0800 704-3737

e-mail: editoraforum@editoraforum.com.br site: www.editoraforum.com.br 


\title{
Derechos Humanos y Corrupción Administrativa*
}

\author{
Augusto Durán Martínez \\ Decano Emérito y Profesor Titular de Derecho Administrativo de la Facultad de Derecho de la \\ Universidad Católica del Uruguay Dámaso Antonio Larrañaga y Profesor de Derecho Público de la \\ Facultad de Derecho de la Universidad de la República
}

1 Desde hace un tiempo he manifestado gran preocupación por el tema a través de varios trabajos. ${ }^{1}$ No voy a repetir lo dicho en ellos, por lo que a esas publicaciones me remito. Ahora me limitaré a profundizar algunos conceptos en el marco de los lineamientos allí trazados.

2 Advierto desde ya que algunos sentirán cierta desilusión al oír mi exposición pues no voy a referirme a grandes, sonados y evidentes casos de corrupción que algunos puedan estar pensando. No porque ellos no me preocupen. Me preocupan por cierto, pero considero que por lo menos en nuestro medio, aunque se han incrementado, constituyen todavía casos aislados. Mucho más me preocupan otras conductas que por su alarmante generalización hacen imposible un pleno desarrollo de los derechos humanos. En esas conductas centraré entonces mi exposición.

\section{II}

1 Al tratar estos temas, González Pérez decía: "Es tal el nivel de degradación de los valores éticos en las Administraciones públicas, que parece que la cuestión se centra en la corrupción. Cuando ésta constituye

\footnotetext{
* Exposición formulada en el Ministerio de Relaciones Exteriores el 18 de abril de 2002 en el marco del Seminario: "Derechos Humanos y Corrupción" organizado por URUGUAY TRANSPARENTE.

DURÁN MARTíNEZ, A. La proyección del derecho internacional de los derechos humanos en el derecho administrativo uruguayo, en DURÁN MARTÍNEZ, A. Estudios sobre derechos humanos. UCUDAL - Ingranusi Ltda., Montevideo, 1999, pp. 89 y ss.; Suspensión del plazo de la caducidad del ejercicio de la potestad sancionatoria de la administración, en DURÁN MARTÍNEZ, A. Estudios sobre..., pp. 103 y ss.; Corrupción y derechos humanos. Aspectos de derecho administrativo (Convención Interamericana contra la Corrupción) en DURÁN MARTíNEZ, A. Estudios sobre..., pp. 119 y ss.; Corrupción y derechos humanos. Aspectos de derecho administrativo (Ley No 17.060, de 23 de diciembre de 1998), en DURÁN MARTíNEZ, A. Estudios sobre..., pp. 133 y ss.
}

A \& C R. de Dir. Administrativo e Constitucional, Belo Horizonte, ano 4, n. 15, p. 39-54, jan./mar. 2004 
tan sólo uno, aunque sea el más grave, de los atentados a la Ética en que puede incurrir un servidor público. Pero existen otros muchos que, ante la generalidad de aquélla, han quedado relegados al olvido o considerados leves pecados veniales, o hasta prácticas administrativas que no vale la pena desterrar." 2

2 Sin perjuicio de algunas precisiones que luego efectuaré, destaco que el maestro español plantea la cuestión en sus justos términos. La corrupción es un atentado a la Ética, lo que nos obliga a trasladarnos a ese plano.

Y en ese terreno Gros Espiell recordaba:

... es imposible concebir una ética que no se base en el respeto de los derechos de cada ser humano, por el Estado y por los demás hombres, en la comprensión de que su naturaleza es el resultado de una idea de lo que es el hombre en su relación con la organización política, de que estos derechos son una emanación de la dignidad eminentemente de la persona y qué derechos y deberes se han de integrar correlativamente para asegurar un orden de libertad, paz y justicia.

El respeto de los derechos de los demás, como un deber de asegurar mis propios derechos y el respeto de los derechos de todos, es un presupuesto necesario, a su vez, para que el Estado y el Gobierno encuentren su justificación. Puede decirse que esto es hoy un principio ético fundamental. ${ }^{3}$

3 La conexión entre la Ética y los derechos humanos aparece así como evidente. Y cuando digo derechos humanos comprendo a todos y no los circunscribo como algunos lo hacen con una evidente finalidad política a determinados derechos de la primera generación; comprendo a todos los de los llamados de primera, segunda y tercera generación y a aquellos que se deriven de la personalidad humana que por nuestras propias imperfecciones hoy los ignoramos pero con nuestro desarrollo cultural podamos descubrir en el futuro.

Es que el hombre, además del "derecho a la vida" posee el "derecho a vivir". ${ }^{4}$

El derecho a vivir o de vivir - decía Gros Espiell - no concierne solamente al comienzo y al fin de la vida. Es un derecho que existe durante toda la vida humana, que le es consustancial y cuya protección debe

\footnotetext{
2 GONZÁLEZ PÉREZ, J. La ética en la Administración pública. Cuadernos CIVITAS, Madrid, 1996, p. 31.

3 GROS ESPIELL, H. Derechos humanos: Ética, Derecho y Política, en GROS ESPIELL, H. Derechos Humanos y vida internacional. Universidad Nacional Autónoma de México - Comisión Nacional de Derechos Humanos, México, 1995, pp. 41 y ss.

4 MONTAND, F. Le recherche du CID pour les concepts du droit à la vie et du droit de vivre, en Actes $d u$ symposium sur LE DROIT A LA VIE. Quarante ans après I'adoption de la déclaration universelle des droits de I'homme: évolution conceptuelle, normative et jurisprudentielle. CID. Genève, 1991, p. 1; DURÁN MARTíNEZ, A. Derechos humanos y medio ambiente, en DURÁN MARTíNEZ, A. Estudios sobre..., p. 109.
} 
extenderse durante toda la misma. La vida tiene una dimensión biológica pero también otras - cultural, económica, social, ética — que se fundan en un contenido integral propio de cada individuo. La vida humana debe ser vivida en la dignidad y en la plenitud de todos los derechos del hombre. ${ }^{5}$

La corrupción pues, como una especie de atentado a la ética, afecta el derecho a vivir y en definitiva supone un desconocimiento de la dignidad humana.

Esto, que por cierto es altamente preocupante, solo puede superarse si no nos olvidamos de la dignidad de la persona humana. ${ }^{6}$

4 La Convención Interamericana Contra la Corrupción y nuestra llamada "ley anticorrupción", ley No 17.060, de 23 de diciembre de 1998, parten de esta concepción.

De la C.I.C.C. muy significativos son los siguientes párrafos del Preámbulo:

CONVENCIDOS de que la corrupción socava la legitimidad de las instituciones públicas, atenta contra la sociedad, el orden moral y la justicia, así como contra el desarrollo integral de los pueblos;

CONSIDERANDO que la democracia representativa, condición indispensable para la estabilidad, la paz y el desarrollo de la región, por su naturaleza, exige combatir toda forma de corrupción en el ejercicio de las funciones públicas, así

\footnotetext{
5 GROS ESPIELL, H. La complémentarité entre les notions de droit à la vie et de droit de vivre, en Acts du symposium..., pp. 5 y ss.; DURÁN MARTÍNEZ, A. Los derechos culturales como derechos humanos en el derecho constitucional uruguayo, en DURÁN MARTÍNEZ, A. Estudios sobre..., p. 32.

6 GONZÁLEZ PÉREZ decía: "O volvemos al verdadero sentido de la dignidad humana y la vinculamos al sentido cristiano, o quedará a merced de los que en cada momento detentan los poderes reales.

Porque la dignidad de la persona no se salva con declaraciones solemnes, que tanto se reiteran en períodos de crisis de desconfianza hacia el futuro, entre la desesperación y la utopía. Ni con su consagración en Constituciones que la rodeen de todas las garantías formales. Únicamente podrá salvarse, y, con ella, el hombre de su destrucción, volviendo a Dios. Pues la raíz última de la angustia del hombre no es otra que la ruptura con Dios, ruptura que le ha dejado en el más absoluto abandono, invadiéndole el miedo ante una soledad que le obliga 'a una precisa determinación y definición de unos derechos, antes sobreentendidos', 'subyacentes en un concepto integral de la persona en el sentido que el cristianismo desde el punto de vista religioso y el tomismo desde el filosófico había tramado alrededor de nuestra esencia'.

La dignidad humana sólo se salvará si el hombre es capaz de recobrar la conciencia del puesto que le ha asignado en el mundo el Creador. Si, consciente de su filiación divina y de la filiación divina de los demás hombres, ve en cada uno de ellos otro yo. Cualquiera que fuere el tipo de relación y el ámbito en que se desenvuelva. Y, muy especialmente, en las relaciones de Poder.

El hombre únicamente recuperará la seguridad y confianza cuando vuelva a tener conciencia de que su dignidad es intangible, no porque así lo haya decidido una Asamblea internacional, un dictador o un Parlamento, sino porque así lo prescribe la Ley eterna. Es intangible porque dimanando directamente de Dios nada ni nadie se la podrá arrebatar.

Y cualquiera que fuera el rango, procedimiento y mayoría con que se hubiere aprobado una disposición que la desconociese o atentase contra ella, quedaría tan sólo en una regla con pretensiones de justicia, que no sería Derecho, sino sólo arbitrariedad y violencia, si se intentara imponer su cumplimiento.

Sólo así encontrará el hombre fuerza para enfrentarse con serenidad a las arbitrariedades de los Poderes Públicos, a la presión de un ambiente social degradante y a las llamadas de lo más bajo de su irracionalidad." (GONZÁlEZ PÉREZ, J. La dignidad de la persona. CIVITAS, Madrid, 1986, pp. 202 y ss.).
} 
como los actos de corrupción específicamente vinculados con tal ejercicio; ...

De aquí se desprende que el combate contra la corrupción no es encarado por la OEA como un fin en sí mismo sino que con él se ha procurado un mejor desarrollo de lo que se ha llamado "el derecho a vivir". ${ }^{7}$ Y por eso con acierto Gordillo vinculó esta Convención con los tratados de derechos humanos. ${ }^{8}$

Algo parecido ocurre con nuestra legislación interna. El Poder Ejecutivo, en el Mensaje que acompañó el proyecto de ley que luego se convirtió en la ley No 17.060 consideró las medidas allí propuestas como "instrumentos destinados a proteger la democracia y la economía". ${ }^{9}$

$\mathrm{Al}$ analizar esta ley, coincidí con el Poder Ejecutivo en cuanto a que la finalidad del combate contra la corrupción es la defensa de la democracia y de la economía. Mas agregué: "Pero ocurre que la democracia y la economía no son fines en sí mismos, sino medios para el mejor desarrollo de la persona humana. Por tanto, el verdadero fin de la lucha contra la corrupción es el desarrollo de los derechos humanos en toda su magnitud. Es que sin democracia, y sin un nivel económico razonablemente adecuado, no puede desarrollarse plenamente la persona humana; no hay así posibilidad siquiera — por lo menos en el mundo de hoy — de hablar de derechos humanos."10

5 Y al llegar aquí es preciso resaltar la importancia de la lucha contra la corrupción en el ámbito de la Administración Pública, objeto específico de este trabajo.

García de Enterría, reflexionando sobre la justicia administrativa, decía: "No es exacto que una buena Administración pueda sustituir una ausencia de Política, o que todo el problema del Estado de Derecho pueda ser reconducido a un problema de justicia administrativa, como alguna vez se ha pretendido, pero sí lo es, sin embargo, que sin una total y plenaria resolución de ese gran tema de la justicia administrativa el Estado de Derecho es literalmente nada. El ciudadano se enfrenta con el Poder primariamente en cuanto poder administrativo. El lo acompaña, como decían nuestros clásicos del siglo XIX, desde la cuna a la sepultura."11

Este contacto entre el poder administrador y el hombre es clave para

\footnotetext{
DURÁN MARTíNEZ, A. Corrupción y derechos humanos... (Convención...), loc. cit., p. 120.

8 GORDILLO, A. Tratado de Derecho Administrativo. Fundación de Derecho Administrativo. Buenos Aires, 1997, t. 1, Parte General, $4^{a}$ edición, p. XVI-7.

9 Diario de Sesiones de la Cámara de Representantes. No 2735, Montevideo, jueves 4 de junio de 1998, p. 22.

10 DURÁN MARTíNEZ, A. Corrupción y derechos... (Ley No 17.060...), loc. cit., p. 136.

1 GARCÍA DE ENTERRÍA, E. La lucha contra las inmunidades del poder. Cuadernos CIVITAS, Madrid, 1995, Tercera edición, p. 12.
} 
un funcionamiento adecuado del Estado de Derecho y en definitiva para el pleno desarrollo de los derechos humanos. Es cierto que no es misión de la Administración administrar justicia, pero debe administrar con justicia. Si hay corrupción administrativa no se administra con justicia y si no se administra con justicia no hay Estado de Derecho; y si no hay Estado de Derecho no es posible hoy en día un desarrollo adecuado de los derechos humanos.

1 González Pérez definió la corrupción "como la utilización de potestades públicas para intereses particulares, cualquiera que sea la forma de manifestarse, sea en beneficio propio o de un tercero o del partido político; sea por razón de amistad o por dinero o por otras prestaciones". ${ }^{12}$

2 Por mi parte he preferido una definición más amplia, entre otras cosas para comprender otras situaciones que trascienden la Administración pública.

Es uno error pensar que la corrupción se circunscribe a la Administración pública. La corrupción en la Administración pública es solo un reflejo de una degradación general de los valores éticos de la sociedad. Por eso con razón el propio González Pérez decía: "asistimos a una quiebra general de los valores morales. En la vida política y en la privada. En el político y en el ciudadano. En el administrador y en el administrado." ${ }^{13}$

En tal sentido definí en otra oportunidad la corrupción como la utilización de una determinada posición, sea cual sea, para obtener para sí o para otro, un beneficio indebido cualquiera sea su naturaleza.

No interesa que el beneficio sea económico para que haya corrupción. No interesa que haya daño al Estado o a la institución a la cual el corrupto pertenece. No interesa tampoco que el sujeto sea funcionario público o no. Lo que importa son dos cosas: a) que un sujeto, en virtud de ocupar una determinada posición, sea cual sea y donde sea, por ello obtenga un beneficio para sí o para otro, que de no tener esa posición no lo habría podido tener; b) que ese beneficio sea ilegítimo. ${ }^{14}$

Si comparamos la definición de González Pérez con la que acabo de exponer, se advertirá que algunas conductas que en el concepto de

\footnotetext{
12 GONZÁLEZ PÉREZ. J. La ética en la..., p. 53.

13 GONZÁLEZ PÉREZ. J. La ética en la..., pp. 22 y 23.

${ }^{14}$ DURÁN MARTÍNEZ, A. Corrupción y derechos... (Ley No 17.060...), loc. cit., p. 138.
}

A \& C R. de Dir. Administrativo e Constitucional, Belo Horizonte, ano 4, n. 15, p. 39-54, jan./mar. 2004 
González Pérez no serían actos de corrupción aunque sí reñidos con la ética, en mi concepto, sí lo serían.

3 El artículo 3 de la ley $\mathrm{N}^{\circ} 17.060$ define la corrupción como "el uso indebido del poder público o de la función pública, para obtener un provecho económico para sí o para otro, se haya consumado o no un daño al Estado." Pero no efectúa una definición con alcance general, sino solo a los efectos del Capítulo II de esa ley. Por eso, nada nos impide emplear nuestra definición en el ámbito administrativo pues ella se deriva en definitiva de una serie de principios generales del derecho de máximo valor formal, como los de imparcialidad, buena fe y probidad, entre otros. ${ }^{15}$

La Convención Interamericana Contra la Corrupción no define la corrupción. De su contexto se advierte que partió de un concepto restringido, pero como prevé un desarrollo progresivo y como el artículo III referido a las medidas preventivas procura una cobertura total a la ética administrativa, ${ }^{16}$ nos alienta a mantener nuestro criterio, al menos a los efectos del Derecho Administrativo.

\section{IV}

1 De una manera general se puede decir que nuestras normas jurídicas perfilan un Estado de Derecho y rectamente aplicadas permiten un adecuado desarrollo de todos los derechos humanos.

Podemos discrepar con alguna solución normativa en particular, pero en sus grandes lineamientos creo que no existen dificultades para que se comparta la afirmación hecha.

Admito también que algunas normas de nuestro sistema - que tuvieron su justificación en su momento - han quedado obsoletas por el transcurso del tiempo, lo que dificulta el desarrollo de nuestro pueblo y en definitiva constituyen un obstáculo para una vida en pleno goce de nuestros derechos.

Pero a mi juicio el gran problema radica en la realidad, en la falta de aplicación o en la mala aplicación del Derecho. Aquí está el talón de Aquiles de los derechos humanos en el Uruguay. ${ }^{17}$ Es que se ha formado lo que Gordillo ha denominado "la administración paralela"18 totalmente al

\footnotetext{
15 DURÁN MARTínEZ, A. Corrupción y derechos... (Ley No 17.060...), loc. cit., p. 138

${ }^{16}$ DURÁN MARTÍNEZ, A. Corrupción y derechos... (Convención...), loc. cit., p. 131.

${ }^{17}$ DURÁN MARTíNEZ, A. La proyección del derecho internacional..., loc. cit., p. 101

18 GORDILLO, A.A. La administración paralela. Cuadernos CIVITAS, Madrid, 1997.
}

A \& C R. de Dir. Administrativo e Constitucional, Belo Horizonte, ano 4, n. 15, p. 39-54, jan./mar. 2004 
margen del Derecho, con sus normas y principios propios, incompatibles con el sistema jurídico formal.

De ella bien podría decirse además, lo que Schwartz ha recordado acerca de la repartición pública norteamericana: "la repartición es una gran organización oscura con la cual el ciudadano tiene que tratar. Es absolutamente amorfa. El la aprieta en un lugar y ella aparece en otro. Nadie parece tener autoridad específica. Hay alguien llamado la comisión, la superioridad (authority); un ente metafísico que parece flotar en el aire y no es un ser humano. Eso es lo que es desconcertante..." 19

Siendo así las cosas no hay que ser muy sagaz para advertir que la Administración actúa con una total impunidad.

Es cierto que estos problemas no son nuevos ni se circunscriben a nuestro país; lo expresado por González Pérez ${ }^{20}$ y Gordillo ${ }^{21}$ es muy elocuente. Pero considero que lo que se vive en el Uruguay de hoy es altamente preocupante.

2 A continuación voy a señalar unos pocos ejemplos de conductas administrativas que afectan los derechos humanos y que a mi juicio configuran actos de corrupción que provocan un daño impresionante.

3 Comienzo con la expropiación.

Nuestra Constitución admite la expropiación. Pero, salvo el excepcional caso previsto en los artículos 231 y 232, la admite mediante el pago de una justa y previa compensación (art. 32).

No hay aquí una operación de compraventa sino una transferencia forzosa de dominio; no hay así un precio sino una indemnización por los daños y perjuicios causados.

Ya Sayagués Laso en su Tratado, hace casi medio siglo, denunciaba que la Administración no cumple adecuadamente la norma. ${ }^{22}$ La Administración normalmente tasa el bien partiendo de los valores catastrales, que como se sabe son por debajo de los precios de mercado, y en la hipótesis más favorable para el propietario tasa desde un escritorio aplicando índices generales prescindiendo de la situación concreta o efectúa una tasación como si fuese una operación de compraventa. En todos los casos la Administración prescinde de los perjuicios causados ignorando claramente el texto constitucional y los derechos humanos.

\footnotetext{
19 GORDILLO, A.A. La administración paralela..., p. 53.

${ }^{20}$ GONZÁLEZ PÉREZ, La ética..., pp. 21 y ss.

21 GORDILLO, A.A. La administración paralela..., pp. 13 y ss.

22 SAYAGUÉS LASO, E. Tratado de Derecho Administrativo, Montevideo, 1959, t. II, pp. 344 y ss.
}

A \& C R. de Dir. Administrativo e Constitucional, Belo Horizonte, ano 4, n. 15, p. 39-54, jan./mar. 2004 
Es cierto que ante discrepancias en definitiva decide la Justicia. Pero el procedimiento jurisdiccional es inevitablemente lento y se dilata una situación que en muchos casos provoca importantes trastornos humanos, tanto personales como familiares, que produce además un considerable daño moral que bien puede evitarse con una adecuada actitud de la Administración. ${ }^{23}$

La cosa se agrava cuando se acude al procedimiento de la toma urgente de posesión. En esos casos, la Administración se hace del bien enseguida y en general procura dilatar lo más posible la fijación judicial del monto definitivo. El bien ya lo posee, lo puede utilizar de inmediato y paga "la próxima Administración".

4 Y hablando de expropiación deseo mencionar otra situación que considero totalmente anómala, aunque admito posee actualmente una cobertura constitucional plausible. Me refiero a expropiaciones efectuadas para actividades económicas del Estado regidas por el derecho de la competencia.

¿Es lógico que el Estado que en determinada actividad compite con los particulares en estricto pie de igualdad por imperio de las normas del derecho de la competencia, disponga de un poder de expropiación que el particular no dispone?

Este se produce porque el artículo 32 de la Constitución tiene su origen en la Constitución de 1830 que concibió un Estado liberal de Derecho. La norma fue reiterada sin variantes esenciales en las Cartas posteriores sin tener en cuenta que con el tiempo el Estado pasó a desarrollar una actividad económica no prevista en nuestra primera Constitución codificada.

Un manejo imprudente de esta potestad puede afectar derechos económicos que son también derechos humanos.

5 Otro aspecto que deseo destacar es en materia de procedimiento administrativo.

Gordillo, al mirar la realidad latinoamericana, advertía que existen algunos países que poseen códigos de procedimiento administrativo Uruguay, entre ellos $-\mathrm{y}$ otros no. Pero verificaba que no hay muchas diferencias reales entre los países que han regulado el procedimiento y los que no lo han hecho. "Es que en verdad — decía — la ley de procedimiento administrativo, aun hecha con el mejor criterio jurídico, no se cumple eficazmente sino en aquello que tiene de limitativo para el particular y de atribución de potestades para la administración pública; en cuanto la ley

${ }^{23}$ DURÁN MARTÍNEZ, A. La proyección del derecho internacional..., loc. cit., p. 96.

A \& C R. de Dir. Administrativo e Constitucional, Belo Horizonte, ano 4, n. 15, p. 39-54, jan./mar. 2004 
introduce criterios de publicidad, razonabilidad, defensa del administrado, control de la actividad administrativa, etc., la realidad en general muy poco recoge de los nuevos preceptos." ${ }^{24} \mathrm{En}$ los aspectos favorables al administrado, bien pueden considerarse las normas del procedimiento administrativo - como decía Gordillo - más que un instrumento social, un instrumento literario. ${ }^{25}$

En este estado de cosas, es muy frecuente que no se dé vista previo a una decisión que crea un perjuicio a un sujeto, y si se da, no se analizan los descargos formulados, y si se analizan los descargos, estos descargos, los dictámenes de los asesores actuantes y la resolución que pone fin al procedimiento parece que formaran parte de un diálogo entre sordos; rara vez se comunica la fecha y hora del interrogatorio de testigos, con lo cual no se puede controlar el diligenciamiento de las pruebas. Todo esto, entre otras cosas, provoca una verdadera situación de indefensión lo que implica una clara violación del derecho de defensa.

Nuestro decreto $\mathrm{N}^{\circ}$ 500/991, de 27 de setiembre de 1991, ha sido muy meticuloso en la fijación de plazos para las actuaciones administrativas. Considera falta administrativa el incumplimiento de esos plazos, pasible de sanción disciplinaria, y establece el deber de determinados funcionarios de fiscalizar el cumplimiento de los plazos y considera falta administrativa la omisión de la fiscalización (arts. 116 y 213 del decreto 500/991).

Esas normas se inspiran claramente en normas internacionales de Derechos Humanos que procuran la instauración de procedimientos de duración razonable. ${ }^{26}$ Es que la vida humana tiene un límite. Y cada hombre tiene derecho a que los procedimientos administrativos que le afecten terminen en un plazo razonable.

Pero lamentablemente esos plazos no se cumplen, nadie fiscaliza nada y no se sanciona a nadie por incumplimiento de los plazos. Parecería hasta que estuviese mal visto sancionar a alguien por este motivo.

Todo esto ocurre tanto en los procedimientos externos como en los internos.

No se puede pensar que la Administración destrata únicamente al mal llamado administrado. También maltrata a sus funcionarios, como un Saturno que devora a sus propios hijos.

En materia de sumarios administrativos, el sumariante más que

\footnotetext{
${ }^{24}$ GORDILLO, A. A. La administración paralela..., p. 50.

25 GORDILLO, A. A. La administración paralela..., p. 103.

${ }^{26}$ DURÁN MARTíNEZ, A. La proyección del derecho internacional..., loc. cit., pp. 95 y ss.
}

A \& C R. de Dir. Administrativo e Constitucional, Belo Horizonte, ano 4, n. 15, p. 39-54, jan./mar. 2004 
descubrir la verdad lo que busca es encontrar culpable al imputado, con lo que distorsiona todos los principios en juego.

Gordillo advertía que a menudo, aparte del legajo formal, existe otro paralelo que denomina "legajo del aire" ${ }^{27}$ que los superiores conocen y en virtud del cual sancionan - o ascienden - y contra el cual es muy difícil ensayar defensa alguna.

Y por cierto los sumarios suelen eternizarse, con lo cual provocan un atentado directo al derecho al honor y en definitiva a la dignidad humana.

Para evitar esto, el decreto $N^{\circ} 500 / 991$, por su artículo 223, previó la clausura de los procedimientos ante la falta de pronunciamiento de la Administración en un plazo de dos años. ${ }^{28}$ Pero lamentablemente un dislatado decreto posterior, el decreto $\mathrm{N}^{\circ}$ 287/998, de 19 de octubre de 1998, introdujo tantas suspensiones a ese plazo que ya no se sabe a ciencia cierta cuándo se produce la clausura de los procedimientos ${ }^{29}$ lo que supone una importante involución en la materia.

6 Otro caso que deseo mencionar aquí es el de los recursos administrativos.

Como se sabe, el agotamiento de la vía administrativa como requisito de admisibilidad de la acción de nulidad surgió en la Constitución de 1952 como una transacción entre el Partido Nacional que pretendía crear el Tribunal de lo Contencioso Administrativo por el propio acto constitucional y el Partido Colorado que quería continuar con la solución vigente que provenía de la Constitución de 1934, que cometía la creación del T.C.A. a la ley, ley que no se había dictado. Las posiciones se aunaron creando el T.C.A. por la propia Constitución pero inventando la vía administrativa a fin de dilatar el acceso a la jurisdicción anulatoria. ${ }^{30}$

Por eso es que aplaudimos lo que con valentía ha expresado Cajarville Peluffo: "así regulados y entendidos, los recursos no son ciertamente una garantía para el lesionado; son un desmedido privilegio de la Administración." ${ }^{11}$ Y por mi parte, he expresado en más de una oportunidad que el agotamiento de la vía administrativa tal como está concebido es un resabio del Estado Absolutista y — adoptando una expresión de REAL — configura

\footnotetext{
${ }_{27}$ GORDILLO, A. A. La administración paralela..., p. 22.

${ }^{28}$ DURÁN MARTÍNEZ, A. La proyección del derecho internacional..., loc. cit., pp. 95 y ss.

${ }^{29}$ DURÁN MARTíNEZ, A. Suspensión del plazo de la caducidad del ejercicio de la potestad sancionatoria de la Administración, loc. cit., pp. 103 y ss.

${ }^{30}$ DURÁN MARTíNEZ, A. Recursos administrativos. Modificaciones dispuestas por la ley No 17.292, en Revista de Derecho, Universidad Católica del Uruguay, NII, pp. 13 y ss.

${ }^{31}$ CAJARVILLE PELUFFO, J.P. Recursos administrativos. F.C.U., Montevideo, 1987, p. 8.
}

A \& C R. de Dir. Administrativo e Constitucional, Belo Horizonte, ano 4, n. 15, p. 39-54, jan./mar. 2004 
una verdadera isla del Estado de Policía dentro del Estado de Derecho. ${ }^{32}$

Pero, si malo es lo que resulta de los textos, peor resulta su aplicación. La Administración en general no actúa con imparcialidad. En lugar de analizar objetivamente si el recurrente tiene razón y dársela en caso afirmativo, habitualmente se siente agredida y se defiende. En lugar de aplicar la razón del Derecho aplica una inexistente e injustificada razón de Estado. En esta concepción, en los hechos casi todos los recursos son rechazados, por lo que sólo sirven para demorar el acceso a la vía jurisdiccional. Los derechos humanos se encuentran así totalmente ignorados.

7 Un último caso que por cierto no agota la lista, pero que debe ser el último por razones de espacio: la actividad de control sobre la actividad privada.

Este control debe existir pues puede ocurrir que la actividad privada pueda eludir las normas en pos de un provecho indebido. Pero también es frecuente que ese control se extralimite y procure por vía indirecta hacer lo que por derecho corresponde al sector privado.

En esta materia se da comúnmente una nota señalada con todo acierto por García de Enterría. La Administración se ve profundamente marcada por su estructura burocrática: “A sus servicios les falta una visión serena y general de las situaciones sociales por la parcialidad de sus respectivas especialidades técnicas y por la dialéctica propia de las disfuncionalidades burocráticas, consustanciales a su misma existencia." ${ }^{3}$

Y lo que es peor es que a través de ese control se produce muy a menudo una verdadera paralización de la actividad privada, que es la verdadera savia de la sociedad.

Los burócratas encargados de ese control frecuentemente piensan en el deber ser, sin advertir que para llegar a él, es preciso primero no dejar de ser. Es común así que para ellos el tiempo no cuenta, mientras que la vida de nosotros, los simples mortales, durante el transcurso de ese tiempo perdido se escurre como el agua entre los dedos de una mano. iY vaya si en esto hay derechos humanos en juego!

\footnotetext{
32 DURÁN MARTÍNEZ, A. El agotamiento de la vía administrativa. Un requisito de admisibilidad de la acción de nulidad. CEDECU. Serie Ensayos No 1, Ingranusi Ltda., Montevideo, 2000, p. 60; DURÁN MARTíNEZ, A. Recursos administrativos..., loc. cit., p. 15.

${ }_{33}$ GARCÍA DE ENTERRÍA, E., ob. cit., p. 83.
}

A \& C R. de Dir. Administrativo e Constitucional, Belo Horizonte, ano 4, n. 15, p. 39-54, jan./mar. 2004 
1 ¿Por qué ocurre esto? ¿Por qué se ha creado este verdadero parasistema, como lo llama GORDILLO? ${ }^{34}$

2 La respuesta no es fácil. Voy a tratar de dar una.

3 El Estado moderno surgió cuando el Estado absolutista luego del Estado feudal logró - como lo enseñaba invariablemente en sus clases mi estimado maestro y amigo, el profesor Héctor Frugone Schiavone - la unificación del poder político, del poder militar y del poder económico.

Si bien esa triple unificación del poder existió - sobre todo si se compara con la realidad medieval —, Giannini señaló que la doctrina europea continental concibió al Estado como un ente, si bien de naturaleza pública en nada distinto de las demás personas jurídicas, con una estructura organizativa unitaria, una voluntad unitaria y una acción unitaria. ${ }^{35}$ Pero enseguida el jurista italiano advirtió que esta construcción dada al Estado no respondía a la realidad, porque - a su juicio - el Estado no actúa nunca unitariamente, como en cambio, sí lo hace un ente público menor. ${ }^{36}$

El Estado - dice - es un conjunto organizado de administraciones diversas, es decir, un ente con administraciones desgregadas y, consecuentemente, con órganos desgregados. Ninguna norma la ha establecido así, pero lo que sucede es que ha nacido así. ${ }^{37}$

Todo ello ha permanecido en el Estado de pluralidad de clases, con una ulterior complicación: que los intereses públicos atribuidos a los diversos Ministerios son en ocasiones institucionalmente conflictivos. ${ }^{38}$

Y la cosa se complica aun más hoy en día en que junto al poder del Estado existen a su juicio otras instituciones con poder público: a) las administraciones internacionales; b) las administraciones supraestatales compuestas por elementos no estatales; c) las administraciones comunitarias; d) los entes representativos de grupos territoriales; e) los partidos políticos; y f) las asociaciones profesionales. ${ }^{39}$

Todo esto hace que existan diversos centros dotados de poderes públicos, con finalidades específicas y diferentes. No es difícil entonces que se produzcan conflictos y es frecuente que la población quede de rehén ante

\footnotetext{
${ }^{34}$ GORDILLO, A. A., La administración paralela..., p. 29.

${ }^{35} \mathrm{GIANNINI}$, M. S. El poder público. Estados y administraciones públicas. Monografías. CIVITAS, Madrid,

1991, pp. 95 y ss.

${ }^{36}$ GIANNINI, M. S., ob. cit., p. 96

${ }^{37}$ GIANNINI, M. S., ob. cit., p. 97

${ }^{38}$ GIANNINI, M. S., ob. cit., p. 97

${ }^{39}$ GIANNINI, M. S., ob. cit., pp. 23 y ss.
}

A \& C R. de Dir. Administrativo e Constitucional, Belo Horizonte, ano 4, n. 15, p. 39-54, jan./mar. 2004 
esos conflictos.

4 Por cierto que estos problemas pueden superarse si tenemos presente la naturaleza humana de donde deriva el poder político y por ende, la comunidad política. El hombre es un animal racional, por ser racional es social y por ser social es político. ${ }^{40}$ De ahí en definitiva deriva el Estado.

La sociabilidad natural del género humano presupone una solidaridad comunitaria en los grupos que se forman, y entre esos mismos grupos. Esta solidaridad se manifiesta en un deber de servicio, no solo al grupo colectivamente considerado, sino entre las personas que lo componen. ${ }^{41}$

El hombre es libre, pero es servidor de los demás... el hombre debe servir para algo y para alguien sin perjuicio de su libertad: es un "ser sirviente" aunque no siervo. ${ }^{42}$

Justamente para mejor servir apareció el Estado. El Estado no es un fin en sí mismo, sino que está finalizado al logro del bien común, o como dijo DABIN con mayor precisión, para el logro del bien común público temporal. ${ }^{43}$ Y la Administración, parte de ese Estado, si bien posee fines específicos, en definitiva ellos se encuentran subordinados a ese bien común que es el fin último del Estado. ${ }^{4}$

De esta forma, teóricamente las diversidades de centros de poder público con sus fines específicos que hacía notar GIANNINI, no impiden la recta ordenación de las cosas al bien común. Pero en los hechos, la realidad muestra que a menudo priman los intereses sectoriales, el bien común queda de lado y los derechos humanos resultan ignorados.

NOUWEN al observar las múltiples actividades destinadas a la ayuda al prójimo nos advertía contra el peligro de que se conviertan en formas de ejercer el poder en vez de ofrecer un servicio. ${ }^{45}$ Esto es lo que ocurre a menudo en la Administración; prima el ejercicio del poder por el poder mismo, con lo cual se emplea para satisfacer el fin de quien lo ejerce, ignorando

\footnotetext{
${ }^{40}$ ARISTÓTELES. La política. Editorial TOR S.R.L., Buenos Aires, 1965, pp. 5 y ss.; DE AQUINO, T. Opúsculo sobre el gobierno de los príncipes, en TOMÁS DE AQUINO, Tratado de la ley - Tratado de la justicia Opúsculo sobre el gobierno de los príncipes. Editorial Porrúa S.A., México, 1975, pp. 257 y ss.; SUÁREZ, F. DEFENSIO FIDEI. El pensamiento político hispanoamericano; Selección de Defensio Fidei y otras obras, Depalma, Buenos Aires, 1966, pp. 20 y ss.

${ }^{41}$ D'ORS, A. Derecho y sentido común. Siete lecciones de derecho natural como límite del derecho positivo. Cuadernos CIVITAS, Madrid, 1995, p. 149.

42 D'ORS, A., ob. cit., p. 152.

${ }^{43}$ DABIN, J. Doctrina general del Estado. Elementos de filosofía política. Editorial JUS, México, 1946, pp. 44 y SS.

44 DURÁN MARTínEZ, A. La prueba en el procedimiento administrativo, en La Justicia Uruguaya. Año 1984, t. 89, S.D. p. 70.

${ }^{45}$ NOUWEN, H.J.M. Tres etapas en la vida espiritual. Un proceso de búsqueda..P.P.C., Madrid, 1997, p. 88.
} 
que solo el poder se legitima si está orientado al fin debido.

5 Esta subversión de fines se facilita por la existencia de una tendencia bastante generalizada a construir una concepción de los derechos en base a una visión subjetivista, propia de la ilustración, en vez de acudirse al realismo clásico claramente objetivista. ${ }^{46}$

6 En cada uno de los ejemplos dados - sin perjuicio de que pueda existir algún motivo de lucro indebido personal del funcionario actuante o un deseo de no contrariar al superior, con lo cual se procura una finalidad personalísima, por cierto indebida - en general existe una finalidad de beneficiar directamente a la institución a la que pertenece el agente o a su jerarca. Y muy a menudo esto se efectúa para fortalecer la posición política del jerarca, o la de un determinado sector político, o del sindicato o de los funcionarios con prescindencia del sindicato, sin tener en cuenta que normalmente esto ocurre en perjuicio directo del interés general. Muy a menudo se invoca el interés público para justificar la actitud de determinado Ente, sin advertir que esa actitud si bien puede favorecer al Ente en cuestión, perjudica los intereses nacionales. En estos casos, como diría Alvaro D’Ors, el poder queda deslegitimado por el abuso de su ejercicio. ${ }^{47}$ Un caso de este tipo fue el que provocó el conocido fallo Pariset del Consejo de Estado francés, de 26 de noviembre de 1875, donde se elaboró el concepto de desviación de poder. ${ }^{48}$

Todo esto es corrupción, y todos estos actos de corrupción en definitiva atentan contra los derechos humanos.

\section{VI}

1 ¿Qué hacer ante esto?

2 Cuentan que un día Miguel Ángel se encontraba esculpiendo. Cuando el mármol ya tenía forma humana, un hombre que miraba le indicó al artista que la nariz era desproporcionada. El escultor trabajó entonces sobre el mentón sin tocar la nariz — sin que el observador se diera cuenta - y al terminar le preguntó cómo había quedado. La respuesta que recibió

\footnotetext{
${ }^{46}$ MASSINI CORREAS, C. I., El concepto de derechos humanos: dos modelos de comprensión y fundamentación, en IUS PUBLICUM, Escuela de Derecho - Universidad Santo Tomás, Santiago de Chile, No 6/ 2001, pp. 33 y ss.

${ }^{47}$ D'ORS, A., ob. cit., pp. 93 y ss.

${ }^{48}$ DURÁN MARTíNEZ, A. El contencioso administrativo francés. Editorial Nuevajurídica, Temas de Derecho Público No 11, Montevideo, 2000, pp. 53 y ss.
}

A \& C R. de Dir. Administrativo e Constitucional, Belo Horizonte, ano 4, n. 15, p. 39-54, jan./mar. 2004 
fue: "ahora sí está perfecta". ${ }^{49}$

La anécdota sirve para demostrar que a veces las soluciones más apropiadas no son las que aparecen a primera vista.

La respuesta más rápida a nuestro problema sería incrementar la represión.

No digo que no deba reprimirse. Hay que reprimir por cierto. Pero precisamente, en algunos de los casos que hemos visto, el derecho prevé sanciones y no se aplican.

Incluso podría pensarse en la posibilidad de crear un Ombudsman pues como con acierto dijo Gros Espiell esta institución "tiene aptitud para promover y proteger, frente a la administración, no solo los derechos civiles y políticos de los individuos, sino también sus derechos económicos, sociales y culturales". ${ }^{50}$

Pero la cosa no pasa únicamente por la represión o la adopción de nuevas formas de control.

3 Desde el momento que González Pérez denuncia la existencia de una verdadera degradación general de valores éticos ${ }^{51}$ - lo que es verdad -; desde el momento que Gordillo advierte con razón la existencia de una alarmante tendencia a violar los grandes principios y normas constitucionales por parte de normas infravalentes $;{ }^{52} \mathrm{y}$ desde el momento que he indicado la existencia de una verdadera subversión de fines en donde es común que los centros que disponen de poder público o los funcionarios actuantes procuran el predominio de su interés específico con prescindencia del bien común, posibilitado en buena medida por una concepción filosófica errónea, no cabe sino concluir que estamos ante un problema cultural. Y un problema cultural solo se combate eficazmente por medio de un adecuado sistema educativo.

4 Un adecuado sistema educativo es aquél que logra trasmitir los valores adecuados. Y estos si no se adquieren en el seno de la familia no hay que olvidarse que la persona humana "encuentra su cuna no solo biológica sino espiritual, en la comunidad de la familia" ${ }^{53}$ — no pueden imponerse por actos de autoridad; solo pueden transmitirse en el marco

\footnotetext{
${ }^{49}$ GORDILLO, A. A. La administración paralela..., pp. 31 y ss.

${ }^{50}$ GROS ESPIELL, H. El Ombudsman en América Latina. Establecimiento de algunas líneas básicas para una legislación uniforme, en GROS ESPIELL, H. Derechos humanos y vida..., p. 170. Ver también CAGNONI, J. A. Control de la Administración. Ombudsman, Comisionado Parlamentario, Mediador, Defensor del Pueblo, F.C.U., Montevideo, 1981.

51 GONZÁLEZ PÉREZ, J. La ética..., pp. 31 y ss.

52 GORDILLO, A. A. La administración paralela..., pp. 23 y ss.

${ }^{53}$ CAFFARRA, C. La familia como ambiente de desarrollo humano, en IUS PUBLICUM..., No 6/ 2001, p. 171.
}

A \& C R. de Dir. Administrativo e Constitucional, Belo Horizonte, ano 4, n. 15, p. 39-54, jan./mar. 2004 
de un sistema que garantice una auténtica libertad de opciones.

Lamentablemente en los hechos no existe una auténtica libertad de elección educativa en nuestro país en ninguno de los niveles de enseñanza, ${ }^{54}$ pese a que la libertad de enseñanza está expresamente garantida por nuestra Constitución (art. 68). Hasta que eso no se logre va a ser muy difícil obtener la formación adecuada que posibilite superar esta degradación ética en que vivimos, que permite una corrupción administrativa de alarmante generalización que provoca un permanente desconocimiento de los derechos humanos.

5 No es este un mensaje pesimista ante esta lamentable realidad sino una invitación a luchar con tesón por la más noble de las causas.

\footnotetext{
${ }^{54}$ DA SILVEIRA, P. La segunda reforma. Por qué necesitamos una enseñanza post-vareliana y como podemos ponerla en marcha. Fundación Banco de Boston - CLAEH, Montevideo, 1995, pp. 63 y ss.; DURÁN MARTínEZ, A. Enseñanza privada y libertad. Bases Constitucionales, en DURÁN MARTíNEZ, A. Estudios de Derecho Constitucional, Ingranusi Ltda., Montevideo, 1998, pp. 62 y ss.
}

A \& C R. de Dir. Administrativo e Constitucional, Belo Horizonte, ano 4, n. 15, p. 39-54, jan./mar. 2004 